\title{
Driving Factors and Implementation Mechanisms for Quality Assurance in the Spanish PhD Adaptation to the Bologna Process - Experience in Mechanical Engineering
}

\author{
Victoria Muerza $^{1}$, Emilio Larrodé2 \\ University of Zaragoza, Zaragoza, Spain
}

\begin{abstract}
The Bologna Process (BP) intends to create a European Higher Education area through the compatibility of degrees in the signatory countries, which has supposed that Universities adapt its studies programmes at all academic levels. In Spain, changes in doctoral studies are structured around five topics: the creation of doctoral schools, competences, tutoring and supervision, collaboration and internationalization, doctoral programmes and duration of studies. This paper analyses how this change have been dealt with in the department of Mechanical Engineering of the University of Zaragoza and the implications in number of students and thesis presented.

The results show that the adaptation to the $B P$ has supposed a quality assurance of the doctoral programme as a consequence of the training activities requirements set by the Academic Committee. The main contribution of the research work is that it reflects how greater control over the drivers of doctoral programmes implies a substantial improvement in the quality of the research work and the thesis.
\end{abstract}

\section{Introduction}

The title of Doctor comes from the Latin word of the same name and meaning, derived from the verb "docere", i.e to teach. The post-nominal letters "Ph.D.", "PhD" or "D.Phil" are used to name it; the academic level varies depending on the country, institution and historical moment.

European Higher Education (EHE) policies, perceived for centuries as matters of national sovereignty, have significantly changed since the Bologna Process [1]. The Bologna Process (BP) is a European intergovernmental higher education project. Its aim is forming the European Higher Education area through the compatibility of degrees in the signatory countries.

The nature of the $\mathrm{PhD}$ and doctoral education is undergoing profound transformations as a result of the BP [2]: different forms of study (professional and practice-based doctorates), new forms of thesis (thesis by publication, creative work plus exegesis), and new kinds of candidates from diverse educational backgrounds. Globalization plays an important role because it facilitates the communication and dissemination of knowledge.

In Spain, the necessary legislative reforms to comply with the requisites of the EHE have been established. This paper shows how these legislative reforms have transformed the doctoral studies and more especially the implications on the transversal training programmes required during the process to develop a doctoral dissertation, followed by a case study of successful implementation. The objective is to identify the implications of the $\mathrm{BP}$ in acquiring competencies during the duration of the doctoral studies. In addition, it presents the mechanism developed by the department of Mechanical Engineering of the University of Zaragoza because of the adaptation to the BP, which has resulted in an improvement of the doctoral thesis presented.

\section{The doctorate programme in the European Higher Education area}

The BP is an essential consideration in approaching the definition of Europe; it expands European borders and promotes the idea of a common European identity [3]. Furthermore, it is developing on the principles of the application of reference points and the diversity and richness of national traditions [4]. This process intends to enhance the attractiveness and competitiveness of the EHE by improving the graduates' competences to face the labour world. The process was initiated in 1999 and 2010 was the year in which all studies had to be adapted to the new structure.

The doctorate programme in the EHE area follows a structure in two levels (see Figure 1): (i) Level 1: training period: through the achievement of a Master degree or its equivalent, a minimum of 60 credits of the European Credit Transfer and 
Accumulation System (ECTS) or by holding a first degree of at least 300 credits. The completion of this level is necessary as a previous step to be admitted in a doctorate programme; and (ii) Level 2: research period: it includes transversal training activities, performing original research, and writing and defence of the dissertation previous getting the doctorate qualification.

However, the European countries have adopted this structure in different ways allowing the creation of different models depending of the objective they pursue. In this regard, Bao et al. [5] distinguish nine models: (i) the research doctorate; (ii) the professional doctorate; (iii) the taught doctorate; (iv) $\mathrm{PhD}$ by published work; (v) the practice-based doctorate; (vi) the "new route" doctorate; (vii) the joint doctorate; (viii) the cooperative doctorate; and (ix) the industrial doctorate.

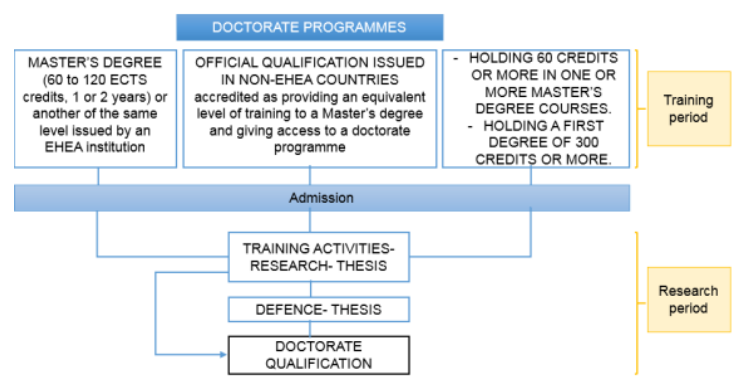

Figure 1. Structure of the doctorate programme in the European higher education area [6]

The existence of different structures implies the existence of different quality assurance processes in all BP countries. These differences are so deep that the application of common standards in some prescriptive way for the actors seems unrealistic [4]. A framework on how $\mathrm{PhD}$ training should be incorporated into the higher education programme is provided by [7], [8], [9]. Ten basic principles have been recognized [7]: (i) advancement of knowledge through original research taking into account market needs; (ii) doctoral programmes must meet new challenges and include appropriate professional career development opportunities; (iii) diversity as a strength which has to be underpinned by quality and sound practise; (iv) doctoral candidates should be recognised as professionals who contribute to the creation of new knowledge; (v) supervision and assessment has a crucial role; (vi) achievement of critical mass and inclusion of innovative practice; (vii) appropriate time duration: three to four years full-time; (viii) promotion of innovative structures: interdisciplinary training and development of transferable skills; (ix) Interdisciplinary and intersectoral mobility, international collaboration through an integrated framework of cooperation between universities and other partners; and $(x)$ appropriate and sustainable funding as a requisite for the development of quality doctoral programme.

\section{Driving factors of the Spanish adaptation to the Bologna Process regarding doctoral studies}

The basic requisites for doctoral studies in Spain are currently being regulated by the Royal Decree (RD) 99/2011 [10]. Five drivers of change have been identified: creation of doctoral schools, competences, tutoring and supervision, collaboration and internationalization, and doctoral programmes and duration.

\subsection{Creation of doctoral schools}

The first doctoral school in Spain, the Barcelona Graduate School of Economics, was created in the year 2006, however the number has increased over the years- from 29 in 2013 to 42 in 2015 [11] as a consequence of the RD 99/2011. The objective of doctoral schools is to organize and manage the training and activities related to the doctoral studies. These functions are performed by a Management Committee composed at least by the Director of the School, the coordinators of the Doctoral Programmes, and representatives of collaborating bodies. Doctoral schools can be individually created or in collaboration between one or several universities with other centres, and institutions and entities with R\&D\&i activities, either public or private, national or international.

\subsection{Competences}

The RD 99/2011 [10] describes a series of competences to be acquired by the doctoral students including disciplinary, methodological and transferrable competencies [12]. However, the competences that can be developed during the doctoral studies are not limited to those gathered in the regulation. Doctoral students are expected to achieve personal maturity and development [13]. In turn, Silvana e Rosa [14] considers the acquisition of competences in both the specialized field of the thesis and in personal and managerial skills. Some of the competences include facing the unknown, quickly extracting and synthesizing knowledge, discovering innovative solutions, solving complex problems, developing strategies by combining multiple perspectives, creativity, networking, communication and quality assessment, time and resource management, as well as failure management.

In this regard, Durette et al. [15] identified a pool of 111 competences organized in six main categories: (i) Knowledge and specialized technical 
skills distinguishing between 'mono-disciplinary' and 'pluridisciplinary'; (2) Transferable competences that can be formalized. They correspond to competencies which can be used in a wide variety of professional situations and acquired through courses. These competences include communication skills, project management, and innovation management; (3) Transferable competences that cannot be formalized. They cannot be acquired through courses. These competences include cognitive abilities, ability to deal with complex problems and ability to collaborate; (4) Dispositions. This category includes aptitudes and qualities that complement transferable competences, i.e. rigor, creativity and autonomy; (5) Behaviors; and (6) Meta-competences, including competences that are useful either to develop one's own pool of competencies or to make a better use of them in professional situations.

On the other hand, Mowbray and Halse [16] introduce the concept of personal resourcefulness to describe the growth in practical knowledge that students acquire during the $\mathrm{PhD}$ and the capacity students develop to act on this knowledge.

\subsection{Tutoring and supervision}

The RD 99/2011 [10] emphasizes the fundamental role of tutoring and supervision in research training. Supervision is concerned with the mechanics of ensuring that the students make good progress towards studies completion [17]. The supervisor is the maximum responsible for the research tasks that the doctoral student must perform. This role is normally carried out by one person. However, in those cases with interdisciplinary development or international collaboration, the supervision task can be carried out by two people with the prior authorization of the academic committee. In recent years, it has been a transition from the perspective of pursuing academic and professional aims towards a market perspective [18].

On the other hand, the tutor is responsible for the adequacy of training and research activity regarding the Doctoral Programme. This role has been specifically created in this regulation, and it still is in process of consolidation (usually the same person takes both roles)

To be allowed to carry out the role of supervisor or tutor, it is necessary accredited research experience in the form of at least one six-year research award or equivalent merits to be evaluated by the Academic Committee [12]. Supervision is seen as a complicated process influenced by many factors, e.g. the social setting, the personalities and the relationship developed between supervisor and student, and the expertise of the supervisor [19]. The two key factors identified by the academic staff in a supervisor's practice are [20]: (i) their concept of research supervision, and (ii) their own experience as a doctoral student.

\subsection{Collaboration and Internationalization}

Internationalization has received much attention in the last years at all levels of education. It is associated not only with quality but also with competition for the best talent [5]. In Spain, doctoral programmes promote the mobility of students and teaching internationalization.

International mobility experiences allow interchange theoretical methods and techniques in a specified discipline, interchange experiences in practice and applications, and broaden knowledge without frontiers [21]. Other measures include welcoming students of other countries, promote stays in foreign universities, incorporate teachers and foreign $\mathrm{PhD}$ students and promote the mention of International Thesis.

The mention of International Thesis implies: (i) performing at least a stay of three months in other research centres and/ or foreign Universities; (ii) to present and defend part of the doctoral dissertation (at least summary and conclusions) in English, which is the usual language for scientific communication; and (iii) to have two reports from international $\mathrm{PhD}$ experts who may not be part of the thesis assessment board. This mention implies that the subject of research covers aspects with international relevance.

In addition, external relations are encouraged. Actions performed include collaboration with other research groups, joint publications between different researchers, and research stays in other centres.

\subsection{Doctoral programmes and duration}

In Spain, the content of the doctoral programmes includes [10]: (i) courses or seminars on the fundamental contents related to the field to which the doctoral programme is dedicated; (ii) courses or seminars related to the methodology and training in research techniques; (iii) supervised research work; and (iv) courses or seminars regarding related fields with interest for the $\mathrm{PhD}$ dissertation project. This type of courses can be classified into three categories [22]: (i) scientific, for the improvement of the scientific background, including summer courses, workshops, high level international courses, and specialized master lectures; (ii) general, which correspond to the improvement of language practice in the scientific fields, preparation to the writing of scientific papers, English communications and (iii) professional, to the preparation of the economic and industrial world. Some examples include the intellectual properties, patents, project management, legal structures of companies, and human resources management. 
The new approach introduced by the RD 99/2011 reduces the variety of departmental Doctoral Programmes to a smaller number, with the objective of training doctoral candidates in scientific research and the possibility of participation to other bodies with R\&D activities [12].

Another novelty introduced by the regulation has been the establishment of a maximum duration of doctoral studies. Full time dedication doctoral studies must be completed in three years. In case of parttime dedication, duration has been set in five years. Exceptions are applied and duration can be extended from one to two years. Some advantages related with the time limit established include [23]: facilitating the development of the scope and timeline for the work to be completed, and planning and acquiring the necessary funding sources for the candidate and their work. According to the same authors, disadvantages are due to the difficulties encountered should unforeseen events, i.e. associated with the line of investigation or personal circumstances, delay the progress of the work, or force a change in experimental direction. These disadvantages can be linked to the fact that a vast majority of doctoral students never complete their dissertation, and very few finish within the stipulated time [24, 25].

\section{Adaptation of the $\mathrm{PhD}$ programme of the University of Zaragoza to the EHEA. Evolution in Mechanical Engineering}

The University of Zaragoza was founded in 1542. It is a public higher education centre distributed geographically in five campuses in the autonomous region of Aragon, in Spain. This University had almost 33,600 students in the academic course 20152016, served by 4,200 academic staff and 1,700 technical and administrative staff.

\subsection{An overview of the PhD studies at the University of Zaragoza}

The University of Zaragoza offers doctorate studies in five areas: Arts and Humanities, Sciences, Health Sciences, Social Sciences and Law, Engineering and Architecture (EA). More currently, the area of EA offers twelve doctoral programmes, among them the programme of Mechanical Engineering. This programme has seven lines of research:

1. Thermal Engineering and Energy Systems.

2. Advanced Materials in Mechanical Engineering.

3. Fluid Mechanics.

4. Advanced Simulation Methods.

5. Modelling of the Mechanical Behaviour of Materials.

6. Transport Systems and Vehicles.

7. Machinery and Mechanical Systems.
Figure 2 and Table 1 shows the evolution in the number of $\mathrm{PhD}$ dissertations and number of $\mathrm{PhD}$ students in mechanical engineering, its comparison concerning EA and the global situation in the University of Zaragoza. The information has been obtained from [26].

The data show a steady increase of doctoral students enrolled in the University of Zaragoza (from 1,960 students in the academic course 2009/ 2010 to 2,636 students in the academic course 2014/2015 (an increment of $34.48 \%$ ). The evolution in EA doctoral students is also positive with exception of the academic course 2013/ 2014. However, this increase is lower $(21.75 \%)$.

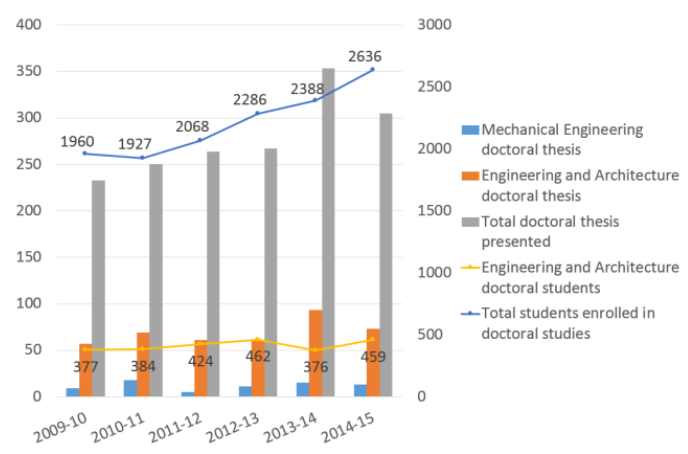

Figure 2. Evolution of doctoral students versus doctoral thesis presented

Table 1. Doctoral thesis presented

\begin{tabular}{lccc}
\hline & $\begin{array}{c}\text { Mechanical } \\
\text { Engineering }\end{array}$ & EA & $\begin{array}{c}\text { Total } \\
\text { University of } \\
\text { Zaragoza }\end{array}$ \\
\hline $2006 / 2007$ & 8 & 32 & 211 \\
$2007 / 2008$ & 11 & 41 & 197 \\
$2008 / 2009$ & 11 & 53 & 225 \\
$2009 / 2010$ & 9 & 57 & 233 \\
$2010 / 2011$ & 18 & 69 & 250 \\
$2011 / 2012$ & 5 & 61 & 264 \\
$2012 / 2013$ & 11 & 60 & 267 \\
$2013 / 2014$ & 15 & 93 & 353 \\
$2014 / 2015$ & 13 & 73 & 305 \\
$2015 / 2016$ & 24 & 93 & 777 \\
\hline
\end{tabular}

On the other hand, in parallel with the increment of number of students, there has been an increment in number of doctoral thesis presented. It is worth noting the increment produced in the academic course 2015/ 2016 with regard to the previous academic course $(84.61 \%$ in the programme of Mechanical Engineering, $27.39 \%$ in EA, and 154.75 $\%$ in the whole University). Undoubtedly, this is due to the extinction of the previous regulation in this academic course.

Section 4.2 and Section 4.3 analyses the ex-ante and ex-post situation in the University of Zaragoza. A special focus has been put on the department of Mechanical Engineering according to the five main 
drivers of change: (i) the creation of doctoral schools, (ii) competences, (iii) tutoring and supervision, (iv) collaboration and internationalization, (v) doctoral programmes and duration of studies, with a special focus on the transversal training programmes required during the process to develop a doctoral dissertation.

\subsection{Ex-ante situation}

Before the full adaptation of the doctoral studies to the Bologna Process, in Spain they were regulated by the RD 778/98 [27]. In the University of Zaragoza, this regulation was extinguished in the academic year 2015/2016. The initial situation shows the following data:

(i) Doctoral school: the University of Zaragoza had not considered this scheme before the BP. The University departments were responsible for the supervision, academic responsibility and coordination of the doctoral programmes.

(ii) Competences: the regulation did not specifically recognize the acquisition of competences as a consequence of carrying out doctoral studies.

(iii) Tutoring and supervision: this role was carried out by the director of the doctoral dissertation. However, the previous training period did not consider this role.

(iv) Collaboration and internationalization: although the regulation considered the possibility to perform agreements with other Universities at international level, it did not specifically promote the performance of these actions.

(v) Doctoral programmes and duration: the regulation considered the same typology of courses showed in Section 3.5. The department of Mechanical Engineering of the University of Zaragoza offered five doctoral programmes:

1. Civil Engineering.

2. New Technologies in Automotive Engineering.

3. Design and Development of Injected Plastic Components.

4. Technologies of Air Conditioning and Energy Efficiency.

5. Computational mechanics.

The structure of the doctoral programmes considered two periods (at least 32 credits): (i) teaching period- minimum 20 credits. Although the nature of the courses was regulated by the $\mathrm{RD}$ $778 / 98$ as previously explained, in practice the contents were related to the field to which the doctoral programme was dedicated; and (ii) research period- minimum 12 credits, where one or several research works were carried out. After finishing these periods, before the development of the doctoral dissertation, it was necessary to obtain the diploma of Advanced Studies. This certificate was awarded after the presentation of the research performed during the research period to a tribunal, which was the starting point of the doctoral dissertation.

The regulation established a minimum duration of two years, however there was not established a maximum duration to finish the $\mathrm{PhD}$ studies.

\subsection{Ex-post situation}

The drivers of the Spanish adaptation to the BP regarding doctoral studies have been defined in Section 3. This Section focus on the analysis of those specific factors in the University of Zaragoza and the department of Mechanical Engineering.

The University of Zaragoza created a doctoral school in 2012. In addition, the department of Mechanical Engineering created an Academic Committee (AC) composed of five department professors responsible for controlling and evaluating the compliance of the doctorate programme.

The tutoring and supervision of the doctoral student is carried out by the same person, which is responsible of this labour until the student presents the $\mathrm{PhD}$ dissertation.

Doctoral students performing their studies within a research group of the department of Mechanical Engineering are further encouraged to have mobility experiences in collaboration with other Universities partners. This is a way to strengthen the relationship between both parties and promote the realization of research projects. In addition, all doctoral students can apply to the mobility scholarships available at the University and at national level to fund their expenses.

More currently, as a consequence of the adaptation of the University of Zaragoza to the BP, there has been a restructuration of the doctorate programmes. Therefore, the Department of Mechanical Engineering has integrated its five doctoral programmes existent in 2009, into a single doctoral programme with seven lines of research:

1. Thermal Engineering and Energy Systems.

2. Advanced Materials in Mechanical Engineering.

3. Fluid Mechanics.

4. Advanced Simulation Methods.

5. Modelling of the Mechanical Behaviour of Materials.

6. Transport Systems and Vehicles.

7. Machinery and Mechanical Systems.

The programme has the following singularities:

- A distinctive drive for quality research that results in publications and patents.

- The transfer of results to the industry, whether regional, national or international. 
- The international scope of academic activity through cooperation with foreign institutions, and the exchange of students and researchers.

The programme is fostered by the following departmental sections at the University of Zaragoza: Transport Infrastructure and Engineering; Mechanical Engineering; Heat Engines; Applied Mathematics; Fluid Mechanics; and Continuum and Structural Mechanics.

The main characteristics of the programme include:

(1) Research period contents: Table 2 shows the structure and dedication in hours of the activities to be performed. In some cases, the AC may 'validate' training activities, for example when the candidate can demonstrate the acquisition of the corresponding skills through self-learning.

In comparison with the ex-ante situation, it can be seen a clear focus on the acquisition of competences, diffusion of research, internationalization and standardization of quality due to the obligation to publish at least two papers in journals gathered in the Journal Citation Report (JCR).

Table 2. Training Activities Requirements of the Mechanical Engineering doctorate programme

\begin{tabular}{|c|c|}
\hline Activity & Control \\
\hline $\begin{array}{l}\text { A1. Presentation of two 30-minute } \\
\text { public seminars, one in the second year } \\
\text { of the studies and another in the third, } \\
\text { on the subjects of the doctoral } \\
\text { research. }\end{array}$ & 10 hours \\
\hline $\begin{array}{l}\text { A2. Assistance to seminars, workshops } \\
\text { or talks about aspects that are state of } \\
\text { the art in any of the program lines. }\end{array}$ & $\begin{array}{l}\text { At least one } \\
\text { per semester }\end{array}$ \\
\hline $\begin{array}{l}\text { A3. Courses or workshops on } \\
\text { computer tools essential for research in } \\
\text { Mechanical Engineering. }\end{array}$ & $\begin{array}{l}\text { At least } 15 \\
\text { hours }\end{array}$ \\
\hline $\begin{array}{l}\text { A4. Courses or workshops to promote } \\
\text { the acquisition of transversal skills } \\
\text { (e.g. Oral and written communication } \\
\text { of scientific knowledge; technical- } \\
\text { scientific English; database } \\
\text { management; researcher ethics; } \\
\text { preparation of scientific research } \\
\text { proposals). }\end{array}$ & 15 hours \\
\hline $\begin{array}{l}\text { A5. Preparation and presentation of } \\
\text { papers in congresses and conferences. }\end{array}$ & $\begin{array}{c}10 \text { hours }(2 \\
\text { presentations })\end{array}$ \\
\hline $\begin{array}{l}\text { A6. Research stays in other research } \\
\text { groups, or in companies. }\end{array}$ & $\begin{array}{c}\text { Min. } 180 \\
\text { hours (1 } \\
\text { month) }\end{array}$ \\
\hline $\begin{array}{l}\text { A7. Publications in international } \\
\text { journals and/ or patents }\end{array}$ & At least two \\
\hline
\end{tabular}

(2) Duration: the doctorate programme lasts a maximum of three years, full time, starting from the admission of the candidate to the program until the defence of the doctoral thesis. However, with the prior authorization of the $\mathrm{AC}$, it can be undertaken part-time doctoral studies, with a maximum duration of five years from admission to the presentation of the doctoral thesis. In practice, this has supposed a challenge for the students from a twofold: on the one hand, in the last years, and before the adaptation to the BP, the department had observed an increasing number of students who after obtaining the diploma of Advanced Studies were working on an "eternal" thesis (even more than 10 years). With the adaptation to the BP this problem has ended. On the other hand, the necessity to publish two papers and finish the thesis in three years is sometimes difficult due to the different nature in research and publishable findings, and the necessity to acquire the competences (from theory to practice) that allows writing a scientific report.

Finally, in addition to the University Program, Spain offers the possibility to carry out an "Industrial Doctorate". The candidate must comply with the following requirements: (i) have a labour or commercial contract with a company from the private or public sector; (ii) participate in an industrial research or experimental development project which is being developed in the company; (iii) the project has to be directly related to the thesis carried out by the candidate.

The doctoral programme in Mechanical Engineering aspires to be a quality doctorate. As part of the contribution of its doctorate students to achieve this quality, this programme expects:

- The doctorate results in relevant technical and scientific advances, evidenced by the publication of at least two articles in prestigious journals ('indexed') and / or in the production of two patents.

- The establishment of high-quality scientifictechnical relations with other research centres or companies, both national and (preferably) foreigners, normally through (at least) one research stay, during the duration of the studies.

- The communication of the generated knowledge (articles, thesis, and presentations) is technically rigorous and linguistically correct.

\section{Proposal of mechanisms to control the quality of research within the doctoral programme}

The application of the BP has implied the restructuration of the doctoral programmes. This section analyses the most relevant aspects in the new configuration for the assurance of the quality of research in the Spanish adaptation. Two main types of mechanisms have been identified: (i) those related to the control of the quality of the research work; and 
(ii) criteria related to the evaluation of research and development plans for thesis project proposals.

\subsection{Mechanisms for the control of quality of the research work}

The aspects that favour a better control of the quality of the research work are the following:

(1) The integration of previous doctoral programmes of specific research lines into more general programmes with a greater scope within their area of knowledge, thus generating programmes with a larger number of students and enabling the participation and collaboration of these in the different joint activities of pre-doctoral training.

(2) The obligatory fulfillment of training activities, the support for the completion of the doctoral thesis, and the possibility of sharing and comparing the developments achieved during the period of completion provide the students with a better knowledge bases and preparation for the development of their own research. In addition, relationship and dissemination activities, inherent to a research development process, are fostered in the new programmes through the need to comply with a series of core and transversal training activities. These training activities have a different nature:

- Training courses on how to approach a research. Scientific method of researching and learning using search tools and gathering information sources.

- Training courses in data analysis tools and work with statistical methods.

- Courses of documents generation and writing of texts with bibliographic citations.

- Specific courses in the area of knowledge related to research, both theoretical and experimental.

(3) The existence of an AC, composed by professors and researchers, that establishes, evaluates and supervises the minimum compliance criteria for the presentation of a thesis project, as a previous step to the completion of a doctoral thesis. Moreover, the continuous control and the possibility of establishing comparisons allow setting up the minimum thresholds to approve the research plans and thesis projects presented, so that a minimum quality for each of the proposals is assured.

(4) The establishment of the evaluation criteria for research projects to ensure that the research proposal presented and the development of future research will follow a proper and well-directed guidance, which justifies the conduct of such research. The AC has the competence to supervise and assess those aspects that may not meet the minimum requirements of quality in the document.

\subsection{Criteria for the evaluation of research and development plans for thesis project proposals}

A set of seven criteria for the evaluation of research, and the development of plans for thesis project proposals have been identified:

(1) The proposal must establish the main novel aspects of the research to be developed, and the main expected results considering new contributions in the field. The thesis project proposal must have a wellwritten and detailed structure and make use of a scientific and rigorous language.

(2) Establishment of a detailed state of the art. It must gather the basic references on which the research is going to be based and the most relevant and close references to the research itself. This will contribute to provide a first criticism about the differential aspects of the research.

(3) Description of the methodology to be used, by providing technical-scientific details in order to evaluate the complexity of the problem to be addressed. In addition, justification of the characteristics of the problem which allow its identification as a research topic, indicating the progress in the state of the art, or the technicalscientific innovations that are expected to be achieved.

(4) Establishment of a work plan for the entire research period. It should include the stages or phases of the research development, and its duration. Furthermore, the definition of the main milestones to achieve throughout the research development process, and periodic review and schedule of the work plan to establish deviations from the initial plan, and details of the major changes that may occur.

(5) Possibility of establishing relations with other studies or research carried out in other institutions, related to the current research. In addition, the possibility of collaboration with other researchers throughout its development.

(6) Program of planned publications on the expected results in journals of high scientific impact, with special emphasis on determining the type of result to be published, and the journal in which it will be disseminated.

(7) Establishment of the scope of the research, the technological scientific means required to perform it, aspects related to training, and necessary information. In addition, specification of the need for collaborations with other researchers or other complementary activities to achieve the expected result.

The mechanisms described above have been implemented in the new configuration of the doctoral programmes. Its application to the thesis project of doctoral students allows having a control of the quality of the proposals and the research in course. 
As a result, the quality of the thesis presented in recent years has improved, and the number of thesis defended has incremented.

\section{Conclusions}

The Bologna Process, aimed to create a European Higher Education area, has implied the adaptation of the studies programmes of the Universities at all levels, making compatible the degrees in the signatory countries.

The research performed in this paper has analysed the implications of the Bologna Process in the doctoral studies in Spain, and more specifically in the department of Mechanical Engineering of the University of Zaragoza. Changes have been structured around five elements: the creation of doctoral schools, competences, tutoring and supervision, collaboration and internationalization, doctoral programmes and duration of studies. Besides, it has been analysed the evolution in number of students and thesis presented. The results showed an increment in number of students and thesis presented, highlighting the increase of thesis observed in the academic course 2015/ 2016 which can be a consequence of the extinction of the RD $788 / 99$, the regulation previous to the BP.

The analysis of the ex-ante and ex-post situation has shown a decrease of number of doctorate programmes and the assurance of the quality of the programme. For doing this, it has been established common requirements for the acquisition of competences in all research lines in the doctorate programme. Furthermore, it is seen a focus on internationalization and diffusion of research. The requirement of publishing at least two papers in JCR journals is also a novelty.

A maximum studies duration of three years has been established. This measurement has supposed a commitment of students with the programme, but also poses the difficulty of the student depending on the line of research, linked with the acquisition of the necessary competences. Further research is needed to determine if the time set for the duration of studies is the most appropriate. It is worth noting the BP has supposed a professionalization of the doctorate studies through the inclusion of the Industrial Doctorate.

Finally, this paper has shown the bases of the change produced in the doctorate programmes at the Spanish University with the objective of assuring the quality of the research works and thesis. On the other hand, it has been possible to standardize the process of acquiring competencies to achieve the $\mathrm{PhD}$ degree. It is still early for observing conclusive results. However, there are indications showing that adaptations introduced are improving the quality of the thesis carried out. As a consequence, the organizational structure of the doctoral programmes in the University of Zaragoza has been rationalized.

\section{References}

[1] G. Capano, and S. Piattoni, "From Bologna to Lisbon: The Political Uses of the Lisbon 'script' in European Higher Education Policy", Journal of European Public Policy, 18(4), 2011, pp. 584-606.

[2] C. Guerin, A. Jayatilaka, and D. Ranasinghe, "Why start a higher degree by research? An exploratory factor analysis of motivations to undertake doctoral studies", Higher Education Research and Development, 34(1), 2015, pp. 89-104.

[3] I. Kushnir, "The role of the Bologna Process in defining Europe", European Educational Research Journal, 15(6), 2016, pp. 664-675.

[4] J. Jasenek, and J. Cervenová, "A view on the $\mathrm{PhD}$ studies in Bologna Process", 19 ${ }^{\text {th }}$ EAEEIE Annual Conference- Formal Proceedings, 4610175, 2008, pp. 143148

[5] Y. Bao, B. M. Kehm, and Y. Ma, "From product to process. The reform of doctoral education in Europe and China", Studies in Higher Education, DOI: 10.1080/03075079.2016.1182481

[6] Unizar, Postgraduate Programmes Universidad de Zaragoza, 2010, https://goo.gl/05KhHr, accessed January $15,2017$.

[7] European Universities Association, "Bologna seminar: Doctoral Programmes for the European Knowledge Society". Salzburg. 2005. Available at: goo.gl/ZVCTP8, accessed February 20, 2018.

[8] European Universities Association, "Salzburg II Recommendations. European Universities' achievements since 2005 in implementing the Salzburg principles", 2010. Available at: goo.gl/t4eLPJ, accessed February 20, 2018.

[9] Bologna Working Group, "A Framework for Qualifications of the European Higher Education Area". Danish Ministry of Science, Technology and Innovation, Copenhagen, 2005. Available at: goo.gl/ryWRqn, accessed February 20, 2018.

[10] Real Decreto 99/2011, de 28 de enero, por el que se regulan las enseñanzas oficiales de doctorado. BOE. núm. 35 , de 10 de febrero de 2011.

[11] Datos y cifras del Sistema Universitario español, https://goo.gl/YLSAhF, accesed June 25, 2017.

[12] M. Jiménez, "Doctoral studies in Spain: Changes to converge with Europe in the internationalisation of the doctorate", Educational Research and Reviews, 11(23), 2016, pp. 2097-2107.

[13] A. Franke, and B. Arvidsson, "Research supervisors' different ways of experiencing supervision of doctoral 
students", Studies in Higher Education, 36(1), 2011, pp. 719.

[14] A. Silvana de Rosa, "New Forms of International Cooperation in Doctoral Training: Internationalisation and the International Doctorate- One Goal, Two Distinct Models", Higher Education in Europe, 33(1), 2008, pp. 325.

[15] B. Durette, M. Fournier, and M. Lafon, "The core competencies of PhDs", Studies in Higher Education, 41(8), 2016, pp. 1355-1370.

[16] S. Mowbray, and C. Halse, "The purpose of the PhD: theorising the skills acquired by students", Higher Education Research \& Development, 29(6), 2010, pp. 653664.

[17] J. Hockey, "Strategies and tactics in the supervision of UK social science PhD students", Qualitative Studies in Education, 9(4), 1996, pp. 481-500.

[18] P. Bøgelund, "How supervisors perceive $\mathrm{PhD}$ supervision - And how they practice it", International Journal of Doctoral Studies, 10, pp. 39-55.

[19] N. Z. Abiddin, A. Ismail, and A. Ismail, "Effective Supervisory Approach in Enhancing Postgraduate Research Studies", International Journal of Humanities and Social Science, 1(2), 2011, pp. 206-217.

[20] A. Lee, "How are doctoral students supervised? Concepts of doctoral research supervision", Studies in Higher Education, 33(3), 2008, pp. 267-281.

[21] V. Muerza, and E. Larrodé, "Towards the definition of a global logistics engineer. Procedure to establish an international curriculum in Engineering Education", International Journal of Engineering Education, 33(6), 2017, pp. 2071-2082.

[22] O. Bonnaud, and M. Hoffmann, "Needs and management of the complementary courses for $\mathrm{PhD}$ candidates in the field of electrical and information engineering: An answer to economical and industrial world," 2010 9th International Conference on Information Technology Based Higher Education and Training (ITHET), Cappadocia, 2010, pp. 91-94.

[23] J. V. Barnett, R. A. Harris, and M. J. Mulvany, “A comparison of best practices for doctoral training in Europe and North America", FEBS Open Bio, 7(10), 2017, pp. 1444-1452.

[24] E. A. Buttery, E. M., Richter, and W.L. Filho, “An overview of the elements that influence efficiency in postgraduate supervisory practice arrangements", International Journal of Educational Management, 19(1), 2005 , pp. $7-26$

[25] M. Martinsuo, and V. Turkulainen, "Personal commitment, support and progress in doctoral studies", Studies in Higher Education, 36(1), 2011, pp. 103-120.

[26] $\mathrm{PhD}$ studies University of Zaragoza. Stadistics. Available at: goo.gl/mJkUjo, accessed January 15, 2017.
[27] Real Decreto 778/98, de 30 de abril, por el que se regula el tercer ciclo de estudios universitarios, la obtención y expedición del título de Doctor y otros estudios de postgrado. BOE. núm. 104, de 1 de mayo de 1998.

[28] Doctorado en Ingeniería Mecánica. Available at: http://doctoradoim.unizar.es, accessed January 21, 2017. 